\title{
Sentinel Node Mapping in Cervical and Endometrial Cancer: Indocyanine Green Versus Other Conventional Dyes-A Meta-Analysis
}

\author{
Ilary Ruscito, $\mathrm{MD}^{1,2}$, Maria Luisa Gasparri, $\mathrm{MD}^{3,1}$, Elena Ioana Braicu, $\mathrm{MD}$, $\mathrm{PhD}^{2}$, Filippo Bellati, $\mathrm{MD}$, $\mathrm{PhD}^{4}$, \\ Luigi Raio, $\mathrm{MD}^{3}$, Jalid Sehouli, $\mathrm{MD}, \mathrm{PhD}^{2}$, Michael D. Mueller, $\mathrm{MD}^{3}$, Pierluigi Benedetti Panici, $\mathrm{MD}^{1}$, and \\ Andrea Papadia, MD, $\mathbf{P h D}^{3}$ \\ ${ }^{1}$ Department of Gynecology, Obstetrics and Urology, Sapienza University of Rome, Rome, Italy; ${ }^{2}$ Department of \\ Gynecology, Campus Virchow Clinic, Charité Medical University, Berlin, Germany; ${ }^{3}$ Department of Obstetrics and \\ Gynecology, University Hospital of Berne and University of Berne, Berne, Switzerland; ${ }^{4}$ Department of Medical and \\ Surgical Sciences and Translational Medicine, Sapienza University of Rome, S. Andrea Hospital, Rome, Italy
}

\begin{abstract}
Background. Historically, blue dyes, ${ }^{99} \mathrm{Tc}$ or a combination of the two tracers have been used for sentinel lymph node (SLN) mapping in cervical and endometrial cancer patients. Indocyanine green (ICG), as a tracer, has been recently introduced in this setting. Our goal was to assess the differences in overall and bilateral detection rates as well as in false-negative rates among the different tracers. Methods. The electronic databases PubMed, MEDLINE, and Scopus were searched in January 2016 by searching the terms "sentinel lymph node" and "dye" and "indocyanine green," and "cervical cancer" or "endometrial cancer." Series comparing different tracers injected intracervically and reporting the detection rate and/or SLN false-negative rate were selected.

Results. Forty-five studies were retrieved. Six studies including 538 patients met selection criteria. Compared with blue dyes, ICG SLN mapping had higher overall (odds ratio [OR] 0.27; $95 \%$ confidence interval [CI] 0.15-0.50; $p<0.0001$ ) and bilateral detection rates (OR 0.27; $95 \%$ CI $0.19-0.40 ; p<0.00001)$. No differences were found
\end{abstract}

Ilary Ruscito and Maria Luisa Gasparri have contributed equally to this work.

\section{(C) Society of Surgical Oncology 2016}

First Received: 23 January 2016;

Published Online: 9 May 2016

M. L. Gasparri, MD

e-mail: marialuisa.gasparri@uniroma1.it between ICG and ${ }^{99} \mathrm{TC}$, although these results are based on data of a single series. No differences in overall and bilateral detection rates were found between ICG and the combination of blue dyes and ${ }^{99} \mathrm{TC}$. The pooled analysis of false-negative rates data showed no difference in falsenegative rates between tracers.

Conclusions. In cervical and endometrial cancer, ICG SLN mapping seems to be equivalent to the combination of blue dyes and ${ }^{99} \mathrm{TC}$ in terms of overall and bilateral detection rates. Its safety profile and ease of use may favor its employment respect to conventional tracers.

Although sentinel lymph node (SLN) mapping has been investigated in gynecologic oncology for over a decade, it has gained widespread diffusion only recently. ${ }^{1}$ Since 2014, SLN mapping has been recognized by NCCN guidelines as an appropriate surgical lymph node assessment in patients with cervical and endometrial cancer. ${ }^{2,3}$ When substituting a lymphadenectomy with a SLN mapping, an algorithm that includes the removal of any suspicious lymph node and a side-specific lymphadenectomy on every non-mapping hemipelvis in addition to the SLN biopsy is recommended. ${ }^{4,5}$ Because the uterus is a midline structure, its lymphatic flow involves the bilateral pelvic lymph nodes. Hence, the most successful SLN mapping is the one that detects at least a SLN on each hemipelvis. From an oncological perspective, it is crucial that a SLN mapping technique is characterized by low false-negative rates to minimize the risk to undertreat patients. 
Historically, SLN mapping has been performed with ${ }^{99}$ Technetium radiocolloid $\left({ }^{99} \mathrm{Tc}\right)$ alone or in combination with blue dyes. However, these tracers have some side effects. Blue dyes cause discoloration of the skin and urine, a decrease in pulse oximetry readings and occasionally severe allergic reactions. Mapping with ${ }^{99} \mathrm{TC}$ is logistically complicated because of the coordination required between the injection in a controlled environment, the imaging acquisition and the surgery, making this technique more time-consuming and expensive.

Indocyanine green (ICG) is an intravascular confined fluorescent dye that has been used in ophthalmology to visualize the retinal and choroid vascularization for more than 40 years. ${ }^{6}$ Recently, ICG has been used for SLN detection in various tumors with promising. At present, it is still unclear how ICG performs as a tracer for SLN mapping in cervical and endometrial cancer compared with other conventional tracers.

The purpose of this meta-analysis was to compare the efficacy of ICG versus other conventional tracers ${ }^{99} \mathrm{Tc}$, blue dyes or a combination of the two) in terms of overall and bilateral detection rates and false negative rates, in cervical and endometrial cancer patients undergoing SLN mapping.

\section{METHODS}

\section{Data Identification and Selection}

This meta-analysis was performed following the Preferred Reporting Items for Systematic reviews and MetaAnalyses (PRISMA) statement and included all studies without any restriction on publication year. On January 2016, a systematic literature search was performed. Data were identified using the electronic databases PubMed, MEDLINE, and Scopus by searching the terms "sentinel lymph node" and "dye" and "indocyanine green," and "cervical cancer" or "endometrial cancer." All Englishlanguage original reports evaluating the efficacy of SLN mapping with ICG or other conventional dyes $\left({ }^{99} \mathrm{Tc}\right.$, blue dyes or a combination of these two) in patients affected by cervical or endometrial cancer were considered for inclusion. Studies reporting laparotomy, laparoscopic, or robotic surgery for SLN biopsy were all assessed for inclusion. The reference list of original reports and reviews already published also were analyzed to identify other potential studies.

In endometrial cancer, intracervical, hysteroscopic, and subserosal tracer injections for SLN mapping have been described. However, only series in which the tracer for the SLN mapping was injected intracervically were selected due to the overwhelming diffusion of this procedure and its proven correlation with higher detection rates. ${ }^{7-13}$
Only studies comparing the efficacy of SLN mapping with ICG versus blue-dyes, 99Tc or a combination of the two were included in the meta-analysis. Review articles, case reports, video articles, and letters were excluded. Two independent reviewers (IR and MLG) identified and selected the studies based on inclusion and exclusion criteria. Divergent opinions were resolved by consultation between the reviewers with the involvement of a third author (AP).

For each study included in the meta-analysis, the following data were recorded: first author's information, publication year, study design, sample size, type of cancer, type of surgery (robotic, laparoscopy or laparotomy), SLN detection rate, and false-negative rate.

\section{Endpoints}

The primary endpoints were the overall and bilateral detection rates of the different mapping tracers (ICG vs. conventional dyes), expressed in terms of risk failure in detecting at least one SLN and at least one SLN per hemipelvis respectively. We assessed overall and bilateral detection rates of different SLN mapping tracers comparing ICG versus blue dyes only, ICG versus ${ }^{99} \mathrm{Tc}$ only, and ICG versus the combination of blue dyes and ${ }^{99} \mathrm{Tc}$.

The secondary endpoint was the SLN false-negative rate using different mapping tracers. We assessed the SLN false-negative rate comparing ICG versus blue dyes only, ICG versus ${ }^{99} \mathrm{Tc}$ only, and ICG versus the combination of blue dyes and ${ }^{99} \mathrm{Tc}$. For this purpose, only studies reporting SLN false-negative rates on fully staged patients were considered. Studies reporting SLN false-negative rates based on patients who were not subjected to both SLN biopsy and complete lymphadenectomy were excluded.

\section{Statistical Analysis}

Risk failure of overall and bilateral detection of SLNs using ICG versus the other conventional tracers was stratified by studies and the pooled odds ratio (OR) or risk ratio (RR) were calculated using a fixed- or a randomeffects model. A $\chi^{2}$ test for heterogeneity among proportions was performed to assess the presence of statistical heterogeneity between studies. A fixed-effects model was used if statistical heterogeneity was not significant $\left(I^{2}\right.$ value $\leq 50 \%$ ); differently, a random-effects model was adopted. Graphical representation of each study and pooled analysis was displayed by forest plots. The weight that each study provides in the meta-analysis was graphically reported as a square of different size. Confidence intervals (CIs) for each study were symbolized as a horizontal line passing through the square. The pooled OR or RR were represented as a 
lozenge in the forest plot and its size corresponded to the $95 \%$ CI of the OR. A $p$ value $\leq 0.05$ was considered significant. Statistical analysis was performed using Review Manager 5.3 (http://www.cochrane.org).

\section{RESULTS}

Overall, 45 studies were retrieved through the literature search. Among these, 13 (28.9\%) studies were removed as duplicates. Twenty-four $(53.3 \%)$ were excluded after title and abstract evaluation, because two $(4.4 \%)$ studies were not English-language original reports, three $(6.7 \%)$ studies regarded nongynecologic cancers, one $(2.2 \%)$ study was performed on animals, three $(6.7 \%)$ reports were reviews, three $(6.7 \%)$ were case reports, one $(2.2 \%)$ was a video article, one $(2.2 \%)$ was a letter, and ten $(22.2 \%)$ studies did not compare ICG with other conventional tracers. Two (4.4\%) further studies were excluded successively after full-text evaluation. In the first a nonintracervical tracer injection was used, whereas in the second a population that was later reported more extensively was presented. ${ }^{14-16} \mathrm{Six}$ studies $(13.4 \%)$ remained for comparison at the end of the selection process. The PRISMA flow chart summarizing the process of evidence acquisition is presented in Fig. 1. The flow chart maps out the number of studies identified, screened, included, and excluded as well as the reasons for exclusions.

Overall, 538 patients were included. A total of 173 (32.2\%) patients underwent laparoscopic SLN mapping; $318(59.1 \%)$ of the patients underwent a robotic SLN mapping and $48(8.9 \%)$ patients underwent a SLN mapping via laparotomy.

FIG. 1 PRISMA flow diagram on the meta-analysis process
In two series, a combination of tracers was used in the same patient; however, detection rates were reported separately for each tracer, thus allowing extrapolation of the data for each tracer or a combination thereof in each case. In one series, 100 (18.6\%) patients underwent SLN with all the three tracers. ${ }^{12}$ In another series, $35(6.5 \%)$ patients underwent SLN mapping with both ICG and blue dye. ${ }^{17}$ In the other four series, different groups were mapped with different tracers. In these series, SLN mapping was performed as follows: $165(30.7 \%)$ patients underwent ICG SLN mapping, whereas $113(21 \%)$ patients underwent SLN mapping with a combination of blue-dyes and ${ }^{99} \mathrm{TC}$ and $131(24.3 \%)$ patients underwent SLN mapping with blue dyes only. ${ }^{10,13,16,18}$ From one of the selected series comparing SLN mapping with ICG versus blue-dyes, only data on bilateral and not on overall detection rates could be extrapolated. $^{18}$

All six studies included in the meta-analysis reported the number of false-negative cases, but in two studies, data on false-negative rates per tracer used could not be extrapolated. ${ }^{12,18}$ Consequently, these two studies where excluded from the false-negative rate analysis. Furthermore, one study reported the false-negative rate on a SLN algorithm and therefore was excluded from the analysis as well. ${ }^{10}$ The characteristics of the selected studies are listed in Table 1.

\section{Overall and Bilateral Detection Rates}

ICG Versus Blue-Dyes When comparing ICG with blue dyes for SLN mapping, the pooled analysis data showed a significant increase in overall detection rate for ICG SLN

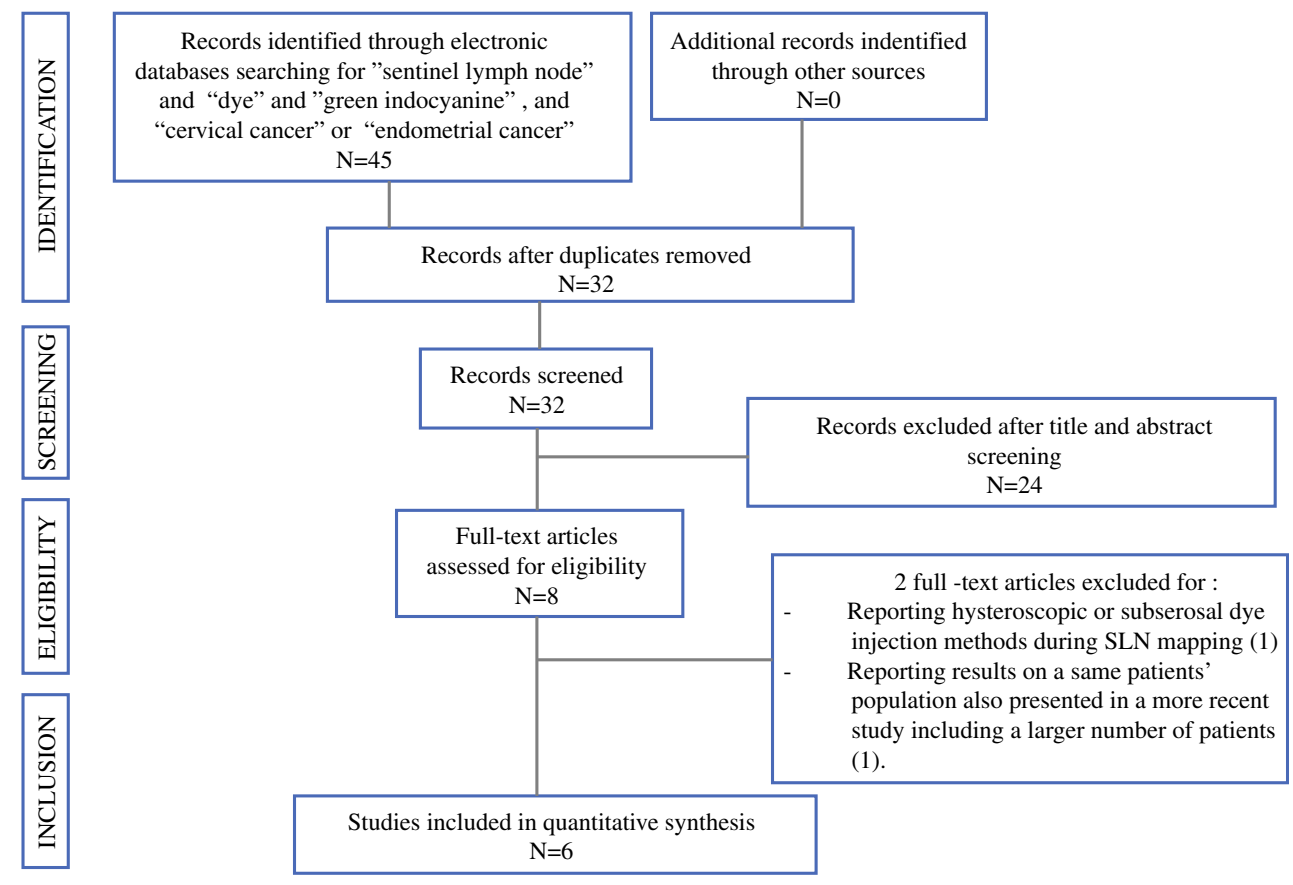




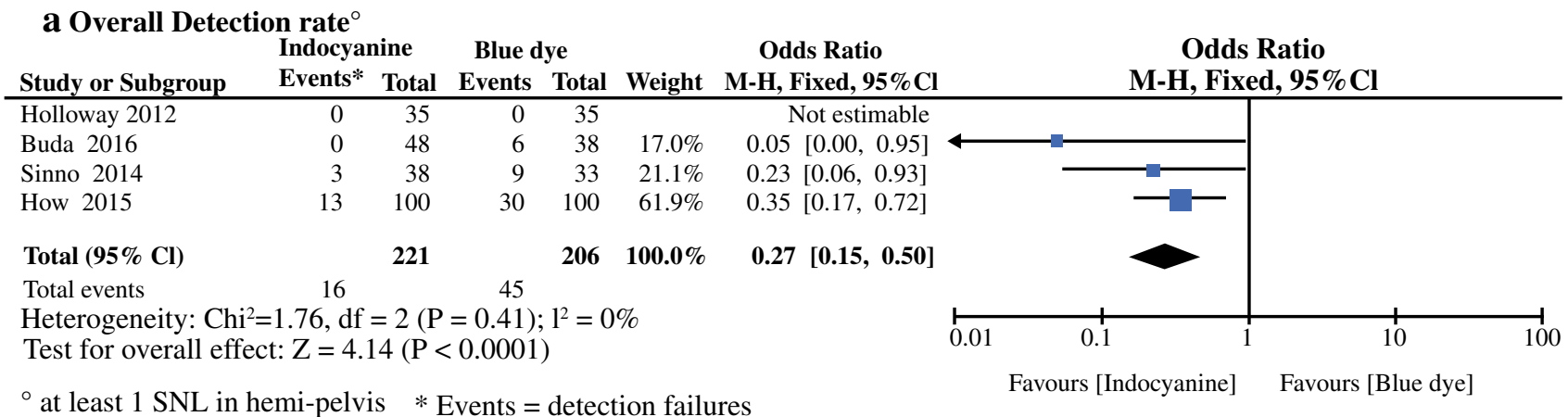

\section{b Bilateral Detection rate ${ }^{\circ}$}



c False negative SLN mapping cases

Indocyanine Blue dye

Odds Ratio

Odds Ratio

Study or Subgroup Events* Total Events Total Weight M-H, Fixed, 95\%Cl Year

Holloway 2012
Buda 2016

Total $(95 \% \mathrm{Cl})$

Total events

Heterogeneity: Not applicable

Test for overall effect: $\mathrm{Z}=1.07(\mathrm{P}=0.28)$

$\begin{array}{cc}0.26[0.02,3.06] & 2012 \\ \text { Not estimable } & 2016\end{array}$

$0.26[0.02,3.06]$

$48 \quad 100.0 \%$

3

$\begin{array}{ll}10 & 100.0 \% \\ 38 & \\ 48 & \mathbf{1 0 0 . 0 \%}\end{array}$



$*$ Events $=\mathrm{N}$ of patients with false negative SLN

FIG. 2 SLN mapping: ICG versus blue dyes. a Overall detection rate. b Bilateral detection rate. c False-negative SLN mapping rates

mapping (OR 0.27; $95 \%$ CI 0.15-0.50; $p<0.0001$, fixedeffect model; Fig. 2a). For bilateral detection rates, the pooled analysis data showed a significant increase for ICG SLN mapping (OR 0.27; $95 \%$ CI 0.19-0.40; $p<0.00001$, fixed-effect model; Fig. 2b).

ICG Versus ${ }^{99} T c$ When comparing ICG with ${ }^{99} \mathrm{Tc}$ for SLN mapping, the pooled analysis data showed no differences in overall detection rates between the two methods (OR 1.08; $95 \%$ CI 0.52-2.26; $p=0.83$, fixedeffect model; Fig. 3a). For bilateral detection rates, the pooled analysis data showed no difference between the two methods (OR 1.21; $95 \%$ CI 0.80-1.81; $p=0.36$, fixedeffect model; Fig. 3b).

ICG Versus Blue-Dyes and ${ }^{99}$ Tc Combined When comparing ICG with ${ }^{99}$ Tc for SLN mapping, the pooled analysis data showed no differences in overall detection rates between the two methods (OR 0.96; $95 \%$ CI 0.45-2.02; $p=0.91$, fixed-effect model; Fig. 4a). For bilateral detection rates, the pooled analysis data showed a nonsignificant increase for ICG SLN mapping (OR 0.37; $95 \%$ CI 0.07-2.12; $p=0.27$ random-effect model; Fig. 4b).

False-Negative Rates When comparing ICG with blue-dyes for SLN mapping, the pooled analysis data showed no difference in false-negative rates between the two groups (OR 0.26; $95 \%$ CI 0.02-3.06; $p=0.28$, fixedeffect model; Fig. 2c). ${ }^{16,17}$

Study comparing ICG versus blue-dyes $+{ }^{99} \mathrm{Tc}$ reported no cases of false-negative SLNs in both groups. ${ }^{13,16}$ When comparing ICG versus ${ }^{99} \mathrm{Tc}$ alone, it is not possible to establish the number of false-negative cases per each group, because the only study comparing these two tracers 


\section{a Overall Detection rate ${ }^{\circ}$}

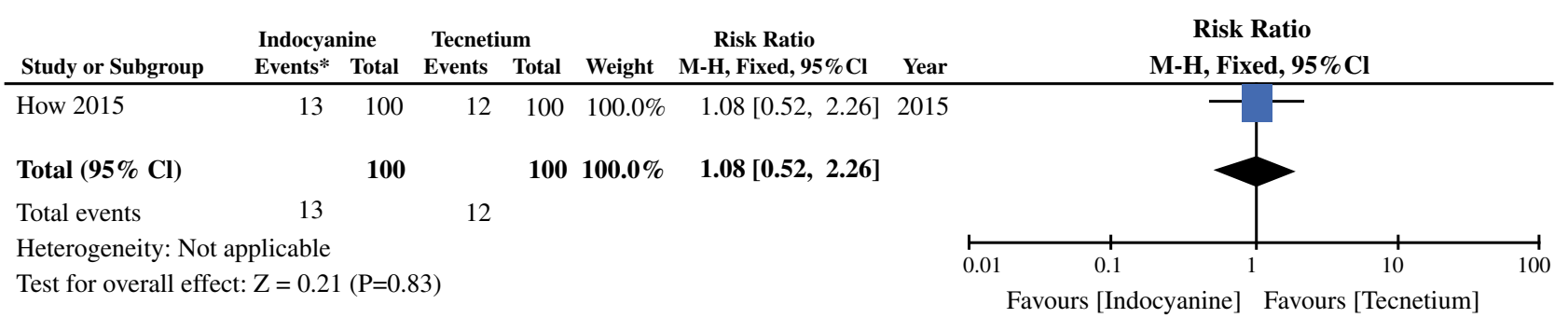

${ }^{\circ}$ at least $1 \mathrm{SNL}$ in hemi-pelvis $*$ Events $=$ detection failures

\section{b Bilateral Detection}

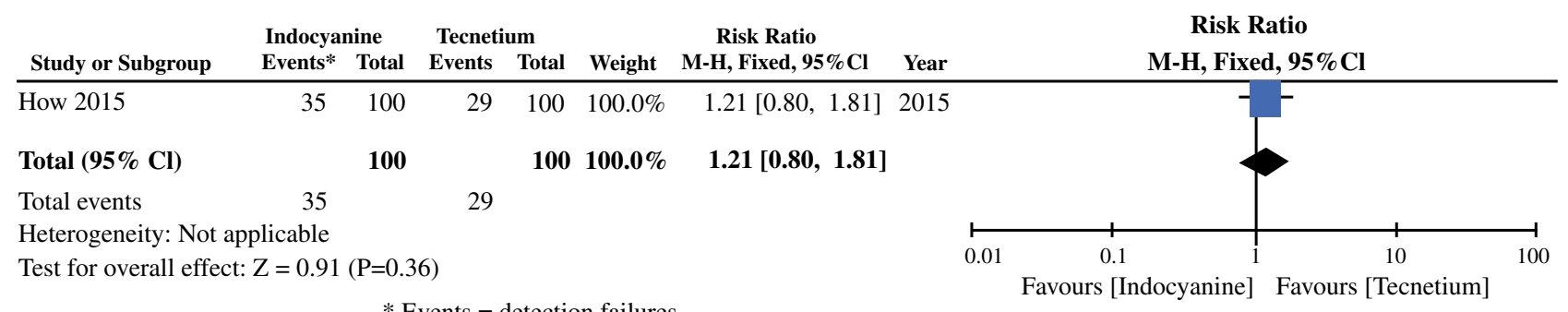

FIG. 3 SLN mapping detection rates: ICG versus ${ }^{99}$ Tc. a Overall detection rate. b Bilateral detection rate

did not specify the type of tracer per reported false-negative SLN. ${ }^{12}$

\section{DISCUSSION}

Different tracers for SLN mapping have been used in cervical and endometrial cancer. The most commonly used are blue dyes and ${ }^{99} \mathrm{TC}$, with detection rates that range between 70 and $100 \%$; however, these data mainly relate to overall detection rates, whereas bilateral detection rates are significantly lower. ${ }^{19,20}$ It has been demonstrated that the combination of blue dyes and ${ }^{99} \mathrm{Tc}$ yields higher detection rates than any of the two tracers alone, with values that are as high as $90 \% .^{21,22}$

Recently, encouraging results with the use of ICG as a tracer for SLN mapping have been reported. ${ }^{8,9,23}$ However, whether ICG is superior to the other conventional tracers alone or in combination for the SLN mapping in uterine malignancies is still an unanswered question.

In the present study, we performed a meta-analysis on series evaluating overall and bilateral detection rates for SLN mapping in uterine cancer using different tracers. We observed that ICG SLN mapping increases both overall and bilateral detection rates by $27 \%$ compared with blue dyes. No differences were recorded in overall and bilateral detection rates between ICG and ${ }^{99} \mathrm{TC}$; however, these results are based on data from a single series. When comparing ICG with the combination of blue dyes and
${ }^{99} \mathrm{Tc}$, no differences in overall detection rate between the two groups were recorded. Although nonsignificant, an improvement in bilateral detection rate for ICG was noted. As far as false-negative rates, no differences were recorded between ICG and other conventional tracers.

When adopting the SLN mapping algorithms for cervical and endometrial cancer proposed by the MSKCC, higher overall and bilateral detection rates will lead to a lower number of side-specific lymphadenectomies on nonmapping hemipelvises. ${ }^{4,5}$ This may ultimately result in a reduction in lymphadenectomy-related surgical morbidity, which has been reported to be as high as $20 \%{ }^{24}$

Cervical and endometrial cancer patients without lymph nodal metastases often do not undergo any adjuvant treatment. In this setting, low to virtually absent false-negative rates are crucial for oncological safety. ${ }^{25}$ Furthermore, it has been demonstrated that the highest NPV for the SLN mapping in early stage cervical cancer is reached in patients with bilateral negative SLN mapping. ${ }^{26}$

In this view, our results are clinically relevant, because they may help physicians to choose which SLN mapping strategy to adopt and to counsel patients with regards to the oncological safety of the procedure and their risk of still undergoing a full lymphadenectomy despite undergoing SLN mapping for their uterine malignancies.

Our results may be accompanied by some limitations. First, surgical approach in the selected studies differed from a laparoscopic, robotically assisted laparotomy. This 
a Overall Detection ${ }^{\circ}$

Indocyanine Combination odds Ratio Odds Ratio

Study or Subgroup Events* Total Events Total Weight M-H, Fixed, 95\% C

\begin{tabular}{lllllll}
\hline Imboden 2015 & 1 & 22 & 6 & 36 & $30.8 \%$ & $0.24[0.03,2.13]$
\end{tabular}

How 2015

Buda 2016

$\begin{array}{rrrrrr}1 & 22 & 6 & 36 & 30.8 \% & 0.24[0.03,2.13] \\ 13 & 100 & 9 & 100 & 55.6 \% & 1.51[0.61,3.71]\end{array}$

Total $(95 \% \mathrm{Cl})$

170

$13.6 \%$

$0.31[0.01,6.62]$

$170 \quad 213 \quad 100.0 \%$

Total events

$14 \quad 17$

Heterogeneity: $\mathrm{Chi}^{2}=3.06, \mathrm{df}=2(\mathrm{P}=0.22) ; 1^{2}=35 \%$

Test for overall effect: $\mathrm{Z}=0.12(\mathrm{P}=0.91)$

${ }^{\circ}$ at least $1 \mathrm{SNL}$ in hemi-pelvis $*$ Events $=$ detection failures

\section{b Bilateral Detection}

Indocyanine Combination

odds Ratio

$0.96[0.45,2.02]$

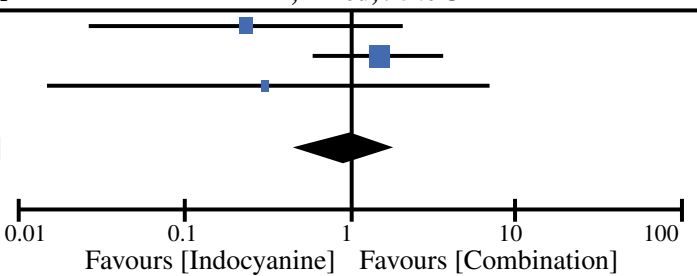

Study or Subgroup Events* Total Events Total Weight M-H, Random, 95\% Cl Year

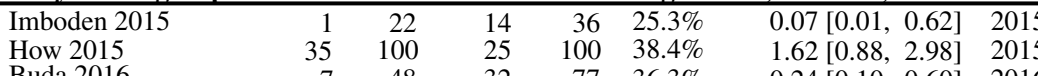

How 2015

Buda 2016

$\begin{array}{ll}1.62[0.88,2.98] & 2015 \\ 0.24[0.10,0.60] & 2016\end{array}$

Total $(95 \% \mathrm{Cl})$

Total events

170

$77 \quad 36.3 \%$

$37[0.07,2.12$

Heterogeneity: $\mathrm{Tau}^{2}=1.96 ; \mathrm{Chi}^{2}=16.81 \mathrm{df}=2(\mathrm{P}=0.0002) ; 1^{2}=88 \%$

Test for overall effect: $\mathrm{Z}=1.11(\mathrm{P}=0.27)$

$$
\text { * Events }=\text { detection failures }
$$

Odds Ratio

M-H, Random, $95 \% \mathrm{Cl}$

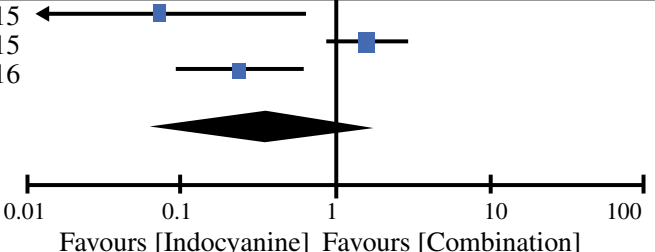

FIG. 4 SLN mapping detection rates: ICG versus blue dyes and ${ }^{99} \mathrm{Tc}$ combined. a Overall detection rate. b Bilateral detection rate

TABLE 1 Characteristics of the studies included in the meta-analysis

\begin{tabular}{|c|c|c|c|c|c|c|c|c|}
\hline $\begin{array}{l}\text { Author } \\
\text { (ref.) }\end{array}$ & Study design & $\begin{array}{l}N \text { of } \\
\text { patients } \\
\text { included }\end{array}$ & $\begin{array}{l}\text { Type of } \\
\text { cancer }\end{array}$ & $\begin{array}{l}\text { Type of } \\
\text { surgery }\end{array}$ & Type of tracers & $\begin{array}{l}\text { Volume of tracer } \\
\text { injected }\end{array}$ & $\begin{array}{l}\text { SLN } \\
\text { count }\end{array}$ & $\begin{array}{l}\text { Mean/median } \\
\text { Pelvic NSLN } \\
\text { count }\end{array}$ \\
\hline $\begin{array}{l}\text { Holloway } \\
\text { et al. }{ }^{17 a}\end{array}$ & Retrospective & 35 & Endometrial & Robotic & $\mathrm{ICG}(35)+\mathrm{BD}(35)$ & $2 \mathrm{ml}$ (ICG), $4 \mathrm{ml}(\mathrm{BD})$ & n.a. & $22.6( \pm 10.9)$ \\
\hline $\begin{array}{l}\text { Sinno } \\
\quad \text { et al. }\end{array}$ & Retrospective & 71 & Endometrial & Robotic & ICG (38); BD (33) & $4 \mathrm{ml}$ (ICG), $4 \mathrm{ml}(\mathrm{BD})$ & $2.23(0-9)$ & n.a. \\
\hline $\begin{array}{l}\text { Tanner } \\
\text { et al. }^{18}\end{array}$ & Retrospective & 111 & Endometrial & Robotic & ICG (57); BD (54) & $4 \mathrm{ml}$ (ICG), $4 \mathrm{ml}(\mathrm{BD})$ & $2.9(0-12)$ & n.a. \\
\hline $\begin{array}{l}\text { How } \\
\quad \text { et al. }{ }^{12 \mathrm{a}}\end{array}$ & Prospective & 100 & Endometrial & Robotic & $\begin{array}{l}\text { ICG }(100)+\text { TC } \\
\quad(100)+\text { BD }(100)\end{array}$ & $\begin{array}{r}0.4 \mathrm{ml} \text { (ICG), } 0.4 \mathrm{ml} \\
\quad(\mathrm{TC}), 3.6 \mathrm{ml}(\mathrm{BD})\end{array}$ & 2.9 & 6.9 (n.a.) \\
\hline $\begin{array}{l}\text { Imboden } \\
\text { et al. }{ }^{13}\end{array}$ & Retrospective & 58 & Cervical & Laparoscopy & $\begin{array}{l}\text { ICG (22); TC + BD } \\
\quad(36)\end{array}$ & $\begin{array}{l}8-10 \mathrm{ml}(\mathrm{ICG}), 120 \mathrm{mBq} \\
\quad(\mathrm{TC}), 5 \mathrm{ml}(\mathrm{BD})\end{array}$ & $2.1-3.7$ & 39 (n.a.) \\
\hline \multirow[t]{2}{*}{$\begin{array}{l}\text { Buda } \\
\text { et al. }{ }^{16}\end{array}$} & \multirow[t]{2}{*}{ Retrospective } & \multirow[t]{2}{*}{163} & $\begin{array}{l}\text { Endometrial } \\
\text { (118) }\end{array}$ & $\begin{array}{l}\text { Laparoscopy } \\
\text { (115) }\end{array}$ & \multirow[t]{2}{*}{$\begin{array}{l}\text { ICG (48); BD (38); } \\
\text { TC + BD (77) }\end{array}$} & \multirow[t]{2}{*}{$\begin{array}{l}4-5 \mathrm{ml}(\mathrm{BD}), 4 \mathrm{ml}(\mathrm{BD}) \\
0.2-0.3 \mathrm{ml}(\mathrm{TC})\end{array}$} & \multirow[t]{2}{*}{$2(0-9)$} & $\begin{array}{c}\text { Endometrium } \\
29(4-54)\end{array}$ \\
\hline & & & $\begin{array}{l}\text { Cervical } \\
\text { (45) }\end{array}$ & $\begin{array}{l}\text { Laparotomy } \\
(48)\end{array}$ & & & & $\begin{array}{l}\text { Cervix } 25(6- \\
58)\end{array}$ \\
\hline
\end{tabular}

$B D$ blue dye, $I C G$ indocyanine green, $T C{ }^{99}$ Technetium, n.a. not available

a All the patients in the series underwent SLN mapping with the same tracers but overall and bilateral detection rates were reported separately for each tracer

may have influenced the detection rates, because the platforms for the ICG-NIR technology are different based on surgical approach. However, the high detection rates recorded in every series suggest that the tracer, rather than the platform, is responsible for the results. Second, both cervical and endometrial cancer patients are included. Although the neoplastic involvement of the cervix may affect the lymphatic uptake of the tracer in patients with cervical cancer, leading to differences in SLN mapping among these and endometrial cancer patients, series including both groups of patients have been published. There does not seem to be a substantial difference among the two scenarios. Additionally, the uterus has a complex lymphatic drainage system based on three anatomical 
pathways: one (the most commonly involved in the lymphatic spread of the disease) draining to the iliac nodes, one draining the fundus mainly via the gonadal vessels to the high paraaortic area, and one draining to the inguinal lymph nodes through the round ligament. ${ }^{27}$ The cervical injection of the tracer therefore may not always represent the best choice for proper mapping in patients with endometrial cancer, especially if this is located in the fundal area. Therefore, some authors recommend a hysteroscopic intratumoral injection of the tracer. ${ }^{28}$ Although a matter of debate, because of the documented marginal risk of isolated para-aortic lymph nodes and because of its "user friendliness," the cervix remains the preferred and most commonly adopted site of injection of the tracer for SLN mapping in endometrial cancer. ${ }^{29}$

\section{CONCLUSIONS}

This meta-analysis demonstrated that ICG SLN seems to be equivalent to the combination of blue dyes and ${ }^{99} \mathrm{TC}$ with in terms of overall and bilateral detection rates in uterine malignancies. The good toxicity profile and ease of use of ICG, which does not require the injection in a controlled environment and an image acquisition before surgery, along with the availability of integrated platforms for minimally invasive approaches that make the SLN mapping easy and intuitive, may favor the choice of this tracer over the combination of blue dyes and ${ }^{99} \mathrm{Tc}$.

CONFLICT OF INTEREST All authors declare no conflict of interest.

\section{REFERENCES}

1. Dargent D, Martin X, Mathevet P. Laparoscopic assessment of the sentinel lymph node in early stage cervical cancer. Gynecol Oncol. 2000;79:411-5.

2. http://www.nccn.org/professionals/physician_gls/pdf/cervical.pdf. Accessed 30 April 2016.

3. http://www.nccn.org/professionals/physician_gls/pdf/uterine.pdf. Accessed 30 April 2016.

4. Cormier B, Diaz JP, Shih K, et al. Establishing a sentinel lymph node mapping algorithm for the treatment of early cervical cancer. Gynecol Oncol. 2011;122:275-80.

5. Barlin JN, Khoury-Collado F, Kim CH, et al. The importance of applying a sentinel lymph node mapping algorithm in endometrial cancer staging: beyond removal of blue nodes. Gynecol Oncol. 2012;125:531-5.

6. Flower RW. Injection technique for indocyanine green and sodium fluorescein dye angiography of the eye. Invest Ophthal. 1973;12:881-95.

7. Kang S, Yoo HJ, Hwang JH, Lim MC, Seo SS, Park SY. Sentinel lymph node biopsy in endometrial cancer: meta-analysis of 26 studies. Gynecol Oncol. 2011;123:522-7.
8. Rossi EC, Ivanova A, Boggess JF. Robotically assisted fluorescence-guided lymph node mapping with ICG for gynecologic malignancies: a feasibility study. Gynecol Oncol. 2012;124:7882.

9. Jewell EL, Huang JJ, Abu-Rustum NR, et al. Detection of sentinel lymph nodes in minimally invasive surgery using indocyanine green and near-infrared fluorescence imaging for uterine and cervical malignancies. Gynecol Oncol. 2014;133:274-7.

10. Sinno AK, Fader AN, Roche KL, Giuntoli RL 2nd, Tanner EJ. A comparison of colorimetric versus fluorometric sentinel lymph node mapping during robotic surgery for endometrial cancer. Gynecol Oncol. 2014;134:281-6.

11. Plante M, Touhami O, Trinh XB, Renaud MC, Sebastianelli A, Grondin K, Gregoire J. Sentinel node mapping with indocyanine green and endoscopic near-infrared fluorescence imaging in endometrial cancer. A pilot study and review of the literature. Gynecol Oncol. 2015;137:443-7.

12. How J, Gotlieb WH, Press JZ, et al. Comparing indocyanine green, technetium, and blue dye for sentinel lymph node mapping in endometrial cancer. Gynecol Oncol. 2015;137:436-42.

13. Imboden S, Papadia A, Nauwerk M, et al. A comparison of radiocolloid and indocyanine green fluorescence imaging, sentinel lymph node mapping in patients with cervical cancer undergoing laparoscopic surgery. Ann Surg Oncol. 2015;22:4198-203.

14. Kataoka F, Susumu N, Yamagami W, et al. The importance of para-aortic lymph nodes in sentinel lymph node mapping for endometrial cancer by using hysteroscopic radio-isotope tracer injection combined with subserosal dye injection: prospective study. Gynecol Oncol. doi:10.1016/j.ygyno.2015.12.023.

15. Buda A, Di Martino G, Vecchione F, et al. Optimizing strategies for sentinel lymph node mapping in early-stage cervical and endometrial cancer: comparison of real-time fluorescence with indocyanine green and Methylene blue. Int J Gynecol Cancer. 2015;25:1513-8.

16. Buda A, Crivellaro C, Elisei F, et al. Impact of indocyanine green for sentinel lymph node mapping in early stage endometrial and cervical cancer: comparison with conventional radiotracer $99 \mathrm{mTc}$ and/or blue dye. Ann Surg Oncol. doi:10.1245/s10434-015-5022-1

17. Holloway RW, Bravo RA, Rakowski JA, James JA, Jeppson CN, Ingersoll SB, Ahmad S. Detection of sentinel lymph nodes in patients with endometrial cancer undergoing robotic-assisted staging: a comparison of colorimetric and fluorescence imaging. Gynecol Oncol. 2012;126:25-9.

18. Tanner EJ, Sinno AK, Stone RL, Levinson KL, Long KC, Fader AN. Factors associated with successful bilateral sentinel lymph node mapping in endometrial cancer. Gynecol Oncol. 2015;138:542-7.

19. Holman LL, Levenback CF, Frumovitz M. Sentinel lymph node evaluation in women with cervical cancer. J Minim Invasive Gynecol. 2014;21:540-5.

20. Cormier B, Rozenholc AT, Gotlieb W, Plante M4, Giede C5; Communities of Practice (CoP) Group of Society of Gynecologic Oncology of Canada (GOC). Sentinel lymph node procedure in endometrial cancer: a systematic review and proposal for standardization of future research. Gynecol Oncol. 2015;138:478-85.

21. Altgassen C, Hertel H, Brandstädt A, Köhler C, Dürst M, Schneider A; AGO Study Group. Multicenter validation study of the sentinel lymph node concept in cervical cancer: AGO Study Group. J Clin Oncol. 2008;26:2943-51.

22. van de Lande J, Torrenga B, Raijmakers PG, Hoekstra OS, van Baal MW, Brölmann HA, Verheijen RH. Sentinel lymph node detection in early stage uterine cervix carcinoma: a systematic review. Gynecol Oncol. 2007;106:604-13. 
23. Papadia A, Imboden S, Siegenthaler F, Gasparri ML, Mohr S, Lanz S, Mueller MD. Laparoscopic indocyanine green sentinel lymph node mapping in endometrial cancer. Ann Surg Oncol. 2016:1-6

24. Conte M, Panici PB, Guariglia L, Scambia G, Greggi S, Mancuso S. Pelvic lymphocele following radical para-aortic and pelvic lymphadenectomy for cervical carcinoma: incidence rate and percutaneous management. Obstet Gynecol. 1990;76:268-71.

25. Papadia A, Imboden S, Fink A, Gasparri ML, Bolla D, Mueller MD. Accuracy of sentinel lymph node mapping after previous hysterectomy in patients with occult cervical cancer. Ann Surg Oncol. 2016:1-7

26. Lécuru F, Mathevet P, Querleu D, et al. Bilateral negative sentinel nodes accurately predict absence of lymph node metastasis in early cervical cancer: results of the SENTICOL study. J Clin Oncol. 2011;29:1686-91.
27. Niikura $H$, Kaiho-Sakuma $M$, Tokunaga $H$, Toyoshima $M$, Utsunomiya H, Nagase S, et al. Tracer injection sites and combinations for sentinel lymph node detection in patients with endometrial cancer. Gynecol Oncol. 2013;131:299-303.

28. Ditto A, Martinelli F, Bogani G, Papadia A, Lorusso D, Raspagliesi F. Sentinel node mapping using hysteroscopic injection of indocyanine green and laparoscopic near-infrared fluorescence imaging in endometrial cancer staging. J Minim Invasive Gynecol. 2015;22(1):132-3.

29. Kumar S, Podratz KC, Bakkum-Gamez JN, et al. Prospective assessment of the prevalence of pelvic, paraaortic and high paraaortic lymph node metastasis in endometrial cancer. Gynecol Oncol. 2014;132(1):38-43. 